\title{
A ciência é uma ideologia?
}

\author{
Gildo Magalhães \\ Professor Titular do Departamento de História - FFLCH - Universidade de São Paulo (USP) \\ gildomsantos@hotmail.com
}

Recebido em 14/03/2016. Aprovado em 18/04/2016.

Como citar este artigo: Magalhães, Gildo. “A ciência é uma ideologia?”. Intelligere, Revista de História Intelectual, São Paulo, v. 2, n 1 [2], p. 100-111. 2016. ISSN 2447-9020. Disponível em < http://revistas.usp.br/revistaintelligere>.

http://dx.doi.org/10.11606/issn.2447-9020.intelligere.2016.112277 Acesso em dd/mm/aaaa.

Resumo: Pretende-se mostrar que, mesmo independentemente de a resposta à pergunta ser positiva ou negativa, no mínimo a atividade científica pode ser ideológica. Para isto é necessário explorar o conceito de ideologia e tentar defini-lo com maior precisão, o que será empreendido a partir de um ensaio de Georges Canguilhem sobre as ideologias científicas. Torna-se interessante e oportuno pensar na questão em sua plenitude e não restrita às ciências sociais, especialmente considerando a pretensa objetividade das ciências naturais.

Palavras-chave: Ciência e ideologia; verdade e falsidade; Georges Canguilhem.

\section{Is science an ideology?}

\begin{abstract}
Independently of giving an affirmative or negative answer to the question, it is intended to show that at least the scientific activity can be ideological. For that purpose it is necessary to exploit the concept of ideology and try to define it more precisely, which will be undertaken from an essay of Geroges Canguilhem about scientific ideologies. It is interesting and adequate to think of this problem in full, not restricted just to social sciences, especially considering the purported objectivity of natural sciences.
\end{abstract}

Keywords: Science and ideology; truth and falsity; Georges Canguilhem. 


\section{A ideologia científica em Canguilhem}

Há um bom número de pensadores que desenvolveram o tema das ideologias, mas quando se trata de sua relação com a ciência se limitam apenas às ciências sociais, e muito poucos se dispuseram a problematizar a relação da ideologia com as ciências naturais ou exatas, ou com as ciências como um todo. ${ }^{1}$ Diferentemente, Canguilhem enfrenta o desafio em um curto e denso trabalho, em que examina as ideologias científicas. ${ }^{2}$

Em seu texto, Canguilhem aponta que a distinção entre o falso e o verdadeiro é um problema epistemológico para a prática da história da ciência que implica no modo pelo qual se constroem os conhecimentos científicos. Como a ciência critica os falsos saberes, seria razoável propor que a ciência é uma crítica das ideologias científicas? Lembra então que a popularização da noção de ideologia decorre da vulgarização do pensamento de Marx, que denuncia as ideologias em nome das ciências da história e da economia política, como pretende instituir. A pergunta passa a ser se uma ideologia científica pode ser compreendida na noção geral de ideologia no sentido marxista e a resposta é que isto seria uma contradição lógica, já que toda ideologia seria ilusória e a ciência revela a realidade, ainda que construída sobre as bases materiais da sociedade.

No entanto, a história é também a história das relações humanas com a natureza, campo das ciências naturais e, portanto, ao contrário das ideologias políticas, uma ideologia científica não é uma falsa ciência, ou uma superstição, ela é uma hipótese que pode ser algum dia demonstrada verdadeira, como por exemplo, o atomismo. As descobertas da química e física a partir do século 19 certamente alteram a ideologia científica anterior. Outros exemplos dados por Canguilhem são a ideologia da hereditariedade do século 18, que desaparecerá em confronto com a teoria mendeliana, e por outro lado a ideologia do evolucionismo social de Spencer, originada da teoria da embriologia de von Baer, reforçada pela teoria darwiniana e transformada num projeto de engenharia social associado ao liberalismo econômico. Neste último caso dá-se o reencontro de uma ideologia científica com o conceito marxista de ideologia.

O autor termina seu texto advertindo que não se deve confundir ideologia científica com ideologia de cientistas. Canguilhem pensa que a ideologia científica sempre antecede uma ciência propriamente dita. Conclui então que a história da ciência precisa investigar também as ideologias científicas e, diversamente de Bachelard, insiste que a história do que já caducou e do que foi sancionado como verdade estão entrelaçadas, e isto livra a história de uma ciência da insipidez e de um quadro de sombras sem relevo. Caso contrário, a história de uma ciência se torna uma... ideologia.

Com esses dados introdutórios, voltamos a examinar esse importante problema iluminado pelas considerações de Canguilhem,

\section{Ideias sobre ideologia}

\footnotetext{
${ }^{1}$ Por exemplo Leandro Konder em A questão da ideologia (São Paulo: Cia das Letras, 2002) arma uma série de comparações entre ideologia de um lado e, de outro, a linguagem, história, psicanálise, arte, ética, política, o cotidiano e o pósmodernismo; significativamente, não avança em nenhuma comparação em termos de ideologia e ciências naturais.

${ }^{2}$ Georges Canguilhem, "O que é uma ideologia científica", conferência proferida em 1969 na Polônia e incluída em Ideologia e racionalidade nas ciências da vida (Lisboa: Ed. 70, s/d), 31-42. Vide também o comentário sucinto a esse texto feito por Pascal Acot em História das ciências (Lisboa: Ed. 70, 2001), 49-51.
} 
Considera-se comumente que o termo ideologia se originou com Destutt de Tracy, que o empregou no sentido de "ciência das idéias" em sua obra Les éléments de l'idéologie (1801). ${ }^{3}$ Então, ao menos originalmente, a equação estava invertida e a ideologia era de fato uma ciência. De Tracy pertencia a um grupo intelectual, os “ideólogos" franceses que, na tradição de Étienne de Condillac, rejeitavam a metafísica e eram adeptos da crença no progresso humano, buscando uma fundamentação antropológica e psicológica para a cultura, tendo apoiado politicamente a ascensão de Napoleão Bonaparte. Mannheim localizou a origem histórica da depreciação que se faz contemporaneamente do termo ideologia na acusação de Napoleão Bonaparte a esse grupo quando se opuseram a seus projetos imperialistas. Eles acabaram alijados do poder pelo próprio Napoleão, que em 1812 os chamou de metafísicos tenebrosos e os acusou de serem responsáveis pela derrota militar francesa na Europa.

Poucas décadas depois do período napoleônico, um dos pais do positivismo contemporâneo e por sinal também inimigo da metafísica, Auguste Comte, adotou um sentido empirista para a palavra, opondo a teoria, como algo que explica, à ideologia, como sendo algo que só expressa. Curiosamente, antípodas políticos de Comte como Marx e Engels também oporiam teoria contra ideologia. É esta a base de sua crítica contra diversos pensadores alemães, exposta em $A$ ideologia alemãa, livro que só foi publicado em 1932, quase cinquenta anos após a morte de Marx, e que contribuiu para popularizar o termo "ideologia" no século XX. Para Marx e Engels a ciência em si mesma não seria uma ideologia (é como se fosse neutra) e o ataque à ideologia era dirigido contra filósofos considerados "idealistas" como Feuerbach, Stirner, Bauer e outros. Marx e Engels estavam preocupados em criticar aqueles que, como Hegel e os jovens hegelianos, a seu ver se divorciavam da realidade e se opunham à concepção materialista, dando predomínio às representações no pensamento puro ao invés da produção material que condiciona a formação dessas ideias. Isto fica claro já no prefácio, quando os autores afirmam ironicamente:

Em tempos, houve quem pensasse que os homens se afogavam apenas por acreditarem na ideia da gravidade. Se tirassem esta ideia da cabeça (...) ficariam imediatamente livres de qualquer perigo de afogamento. ${ }^{4}$

Nesta visão, a consciência reificada, fetichizada, se aliena dos homens que são os verdadeiros produtores de suas ideias. Ou, na formulação concisa de Marx e Engels, não é a consciência que determina a vida, mas sim a vida que determina a consciência, só que as ideologias fazem com que essas ideias pareçam ter uma autonomia. ${ }^{5}$ Os idealistas que promoviam essa alienação deveriam ser novos ideólogos, na tradição dos condenados por Napoleão e, segundo Marx e Engels, seriam os que vêm uma parte da realidade (e isto seria "ideologia") e a tomam pelo seu todo (ver o todo seria possível apenas com uma teoria). Essa conceituação já nos permite fazer uma nova pergunta: será que a ciência, principalmente entendida em seus componentes de ciências naturais e exatas, vê o todo ou parte da realidade? Se em algum momento ela não conseguir ver o todo, estará consequentemente sendo ideológica, de alguma forma?

Houve muitas outras elaborações do que vem a ser uma ideologia. Pode-se nesta altura se utilizar provisoriamente de alguns resultados já extraídos desse debate e se deter em três acepções geralmente bem características do que usualmente se entende por ideologia (mas que logo à frente se mostrará não serem suficientes): ${ }^{6}$

a) A ideologia expressa um conjunto de ideias que se constituem em um imperativo (moral).

\footnotetext{
3 "Ideologia me parece ser o termo genérico porque a ciência das ideias compreende tanto a de sua expressão quanto a de sua derivação" - de Tracy, 1801, apud Karl Mannheim, Ideologia e utopia (Rio de Janeiro: Guanabara, 1986), 97.

${ }^{4}$ Karl Marx e Friedrich Engels, A ideologia alemã: crítica da filosofia alemã mais recente na pessoa dos seus representantes Feuerbach, $B$. Bauer e Stirner, e do socialismo alemão na dos seus diferentes profetas. (Lisboa e S. Paulo: Presença e Martins Fontes, 1980), 8.

${ }^{5}$ Karl Marx e Friedrich Engels, A ideologia alemã, 26.

${ }^{6}$ São as que constam de texto de Marilena Chauí, O que é ideologia (São Paulo: Brasiliense, 1995) - muito difundido no meio universitário, embora não estenda a discussão para além do que certos círculos marxistas decidiram entender como ideologia.
} 
Parece que nesse sentido, mesmo levando em conta um imperativo moral, poder-se-ia traduzir ideologia por "visão de mundo" (Weltanschaunng). Aqui surge outra pergunta à margem do conceito: pode-se dizer que a ciência se associa a um ou alguns imperativos morais, refletindo sua natureza ideológica, ou ao contrário ela seria manifesta e pretensamente "neutra"?

b) Quando posta a serviço de uma dada diretriz sócio-econômica, a ideologia expressa a "consciência" da classe dominante, que por sua vez se transforma em ideia dominante também para as demais classes.

Para essa difusão de ideias dominantes concorre o fenômeno da alienação, descrito também por Marx em várias ocasiões. ${ }^{7}$ Novamente pode-se inquirir se a ciência, agora de acordo com essa definição, não seria mesmo uma ideologia, porque ela comumente se cristaliza num conjunto de ideias dominantes, aceitas de forma paradigmática?

c) A ideologia é uma projeção contínua da infraestrutura sobre a superestrutura, no sentido marxista dessas palavras, que exprimem a influência da base econômica sobre as demais facetas da vida social.

Nesse caso, a ciência pode claramente ser ideológica, já que para ela concorre sempre alguma base material, como aliás sustentam alguns autores de história da ciência, principalmente os da linha externalista.

Pode-se então neste ponto tirar algumas conclusões se quisermos aplicar algum dos três conceitos acima ao caso das ciências. Em primeiro lugar, nesse contexto a palavra ideologia não precisa necessariamente ser tomada pejorativamente. Aliás a primeira definição é bastante geral (pode-se mesmo criticá-la por ser geral demais) para admitir as duas seguintes como casos particulares, e é também suficientemente neutra para não ter forçosamente conotações negativas. Portanto, não será considerada como aberração nem contradição a expressão "ideologia científica"; antes, vamos admiti-la como uma hipótese a ser verificada.

Adicionalmente, é importante compreender o caráter histórico das ideologias. Nesse sentido, a primeira definição é útil, pois por meio dela se pode demonstrar que a produção de ideias (e, por extensão, de ideologias) é historicamente situada e se projeta em todos ramos de atividade humana, tais como artes, religião, ciência, etc.

No sentido algo mais restrito da segunda definição, a ideologia costuma ser associada à falsidade, uma vez que politicamente sempre interessou à classe dominante deformar ideias, para facilitar a persuasão das classes dominadas; torna-se então difícil falar nesse caso em ideologias "verdadeiras". A menos das ocasiões em que deliberadamente se manipulam ideias científicas com alguma finalidade política expressa, essa visão de ideologia pouco adianta no estudo da história da ciência e da técnica. Isto porque, pelo contrário, as ideias científicas não se acham explícita e claramente ligadas a motivações de outra natureza, mas tais interesses se encontram dissimulados ou despercebidos dentro do desenvolvimento racional das ciências, somente se revelando com características claramente ideológicas após um exercício hermenêutico.

Já no sentido da terceira conceituação, pode-se creditar à ideologia um caráter mais construtivo; para dar um exemplo mais extremo, de acordo com esse sentido pode-se acreditar, vivendo numa sociedade capitalista que a construção do socialismo seria também uma "ideologia". Neste caso, inclusive a ciência ou a tecnologia podem ser positivamente associados à transformação da sociedade, como parte dessa ideologia.

\footnotetext{
${ }^{7}$ A primeira menção de Marx à alienação parece que ocorre em "Sobre a questão judaica" in Early writings. (New York: McGraw-Hill, 1964), 19, e sua reelaboração na forma econômica é o tema da famosa seção 4 do capítulo I, Parte I, sobre a fetichização das mercadorias e a reificação da consciência (Capital: a critical analysis of capitalist production (London: Lawrence \& Wishart, 1974, vol. 1), 76-87).
} 
Vejamos agora algumas tentativas de sair do esquematismo das três conceituações apresentadas.

Mannheim afirmou que há duas concepções de ideologia: a concepção particular, com referência à psicologia do indivíduo e onde podem ocorrer fenômenos tais como modos falsos de pensamento e acobertamento de mentiras; e a concepção total, que decorre da vida coletiva, e em que há uma correspondência entre um contexto social e uma dada perspectiva de pensamento e conhecimento. ${ }^{8}$ As ideologias seriam aparentadas com as utopias, das quais se distinguiriam por se voltarem ao passado, serem defendidas pelas classes dirigentes e justificarem e dissimularem a realidade, enquanto que as utopias se voltariam ao futuro, sendo defendidas pelas classes ascendentes e atacarem a realidade com que não concordam. São distinções que para Mannheim aliás nunca são absolutas, porque frisava ao mesmo tempo que a realidade está sempre em mudança.

Em outro momento, naquilo que poderia passar por uma simples briga interna à Escola de Frankfurt, Jürgen Habermas discutiu com Herbert Marcuse em torno de como interpretar a razão tecnicista, a visão de que a técnica e a ciência passaram a legitimar a dominação capitalista, racionalizada pela intervenção do Estado, que com isto passou a cuidar de questões técnicas. $\mathrm{O}$ texto de Habermas resultante dessa discussão trata da técnica e ciência como ideologias, na verdade expandindo uma conclusão a que chegara antes. 9 Para Habermas, as ideias individualmente podem servir para mascarar os motivos reais de nossas ações, o que coletivamente ele chama de ideologia. Entre o sujeito e um objeto haveria sempre um interesse guiando o conhecimento, mesmo na auto-reflexão. Negar isto seria cair na ilusão do objetivismo e neutralidade do conhecimento, ilusão que tem função legitimizadora, uma perspectiva que seria no fundo positivista.

Paul Ricoeur retornou a esses dois autores, Mannheim e Habermas, num texto que se intitula justamente Ciência e ideologia. ${ }^{10}$ Embora ao falar de ciência Ricoeur se restrinja unicamente às ciências sociais, ele lembra que a crítica das ideologias nunca conseguirá se libertar totalmente de seu enraizamento nas próprias ideologias, ou seja, a crítica também é conduzida por um interesse, ainda que seja contraditoriamente o interesse pela libertação ideológica, o que seria em si mesmo uma ideologia ou utopia, dependendo do ângulo de quem a pratica. Só a história a posteriori poderia dizer se se tratava de ideologia ou utopia. Ainda assim, a crítica das ideologias deveria ser empreendida, mesmo que não possa ser completada. $\mathrm{Na}$ fórmula proposta por Ricoeur, o saber está sempre se desligando da ideologia, mas a ideologia permanece sempre como esquema de interpretação do saber.

Uma tipologia proposta por Raymond Boudon classificou as definições de ideologia em dois grandes grupos: as que usam o critério de separar entre verdadeiro e falso (que seria uma linha caracterizada inclusive por Karl Marx, mas também por Raymond Aron e Talcott Parsons) e as que não se referem a este critério (uma outra linha onde se enfileiram Lênin, Louis Althusser, Clifford Geertz e Edward Shils). ${ }^{11}$ Há portanto nessa separação tanto pensadores marxistas quanto não marxistas, de lado a lado. Boudon concluiu que para Marx a ideologia se ligaria diretamente à falsa ciência, enquanto que para Aron a ideologia poderia ser apenas indiretamente julgada em referência ao verdadeiro e ao falso; e Parsons consideraria a ideologia um desvio em relação à objetividade, que a análise científica permitiria restabelecer.

\footnotetext{
${ }^{8}$ Karl Mannheim, Ideologia e utopia, 81- 98.

9 Jürgen Habermas, "Técnica e ciência como ideologia" e "Conhecimento e interesse" em Técnica e ciência como "ideologia" (Lisboa: Ed. 70, 1993), 45-92 e 129-147.

${ }^{10}$ Paul Ricoeur, "Ciência e ideologia", Cadernos de História e Filosofia da Ciência, no 1 (1980): 21-43.

${ }^{11}$ Raymond Boudon, A ideologia: ou a origem das ideias recebidas. (São Paulo: Ática, 1989), 25-46.
} 
$\mathrm{Na}$ outra vertente, Lênin se preocuparia mais com a utilidade das ideologias na luta de classes do que com sua verdade ou falsidade, Althusser consideraria a ideologia como um sistema de representações indispensáveis e com função social, Geertz veria a ideologia como um ato simbólico, um procedimento metafórico e de retórica usado socialmente e, finalmente, para Shils a ideologia seria um tipo de sistema de crenças que existiria em qualquer sociedade. Boudon vai preferir a linha de critério que distingue entre verdadeiro e falso, defendendo que as ideias recebidas que entram na composição das ideologias têm uma racionalidade e que essas ideias recebidas podem resultar das ciências, que ele entende, também diferentemente do que se pretende aqui, unicamente como sendo as ciências sociais. ${ }^{12}$

Finalmente, antes de suspender a discussão sobre a definição de ideologia, e para insinuar como ela pode ainda vir a ser enriquecida, vale a pena uma referência ao livro Ideologia, de Terry Eagleton, por sua abrangência e clareza no tratamento do tema. ${ }^{13}$ Esse autor arrolou nada menos do que 16 sentidos correntes da palavra "ideologia" (e que cobrem inclusive aqueles três primeiros significados apontados atrás), passando a seguir a demonstrar serem todos imprecisos, problemáticos ou contraditórios. Depois de expô-los como inadequados e descartá-los, ele propôs seis definições como sendo mais aceitáveis, indo também de uma primeira de caráter mais geral para as outras cinco, mais particulares. Assim, ideologia poderia ter qualquer uma das seguintes acepções:

i) O processo material geral de produção de ideias, crenças e valores na vida social.

Corresponde portanto a uma noção com semelhanças à de "cultura", entendida esta também como produto de um processo material.

ii) Ideias e crenças, verdadeiras ou falsas, que sintetizam as condições e experiências de vida de um grupo socialmente significativo.

Essa é uma definição que se assemelha à de "visão de mundo".

iii) A promoção e legitimação dos interesses de grupos sociais, em presença de interesses conflitantes.

iv) A promoção e legitimação dos interesses de grupos sociais, restritas às atividades de um poder social dominante.

v) A promoção e legitimação dos interesses de grupos sociais, restritas às atividades de um poder social dominante e mediante distorção e dissimulação.

vi) Crenças falsas oriundas da estrutura material do conjunto da sociedade.

Um exemplo onde esta última conceituação cabe bem é o da ideologia do fetichismo das mercadorias, tal como exposta por Marx juntamente com sua crítica da alienação, já citadas anteriormente.

Uma última palavra sobre a questão de definições é que a complexidade que esta breve discussão deixa entrever mostra que se deve rechaçar simplificações que assumem ser inútil discutir o conceito de ideologia, por ser algo “superado". Não é aceitável nenhum decreto do "fim das ideologias" nem a versão mais refinada que procura encerrar a discussão pela substituição da palavra ideologia por outras palavras, tais como "representações". Há que

12 Raymond Boudon, A ideologia: ou a origem das ideias recebidas, 93.

${ }^{13}$ Terry Eagleton, Ideologia: uma introdução, (São Paulo: Universidade Estadual Paulista e Boitempo, 1997), 38-40. 
enfrentar como problema político, mas também como uma problemática da teoria do conhecimento, muitas questões teóricas e práticas ainda não resolvidas, mesmo após a queda do muro de Berlim, tais como a natureza do Estado burguês, a teoria da luta de classes, e outras em que o conceito de ideologia ainda é, na verdade, central.

\section{Uma radiografia da ideologia}

Uma dificuldade adicional para responder se a ciência pode ser uma ideologia é que, em determinadas fases de seu desenvolvimento, teorias científicas devem permitir a contestação, desde que obedecidas uma série de condições - como ocorreu por exemplo com as teorias geocêntrica e heliocêntrica - e essas contestações permanecem até que uma nova teoria seja aceita por um grupo científico dominante e se firme, ao menos para esse grupo dominante. Ora, que ideologia admite uma abertura para a contestação? Por mais dialética que seja sua base teórica, uma ideologia se pretende "verdadeira" e inquestionável. E no entanto, sabe-se que as ideologias se tornam superáveis, tanto quanto as teorias científicas. Portanto, a ideologia se comporta, malgrado seu, como uma teoria científica, que pode ser escarafunchada, minada ou consagrada num determinado momento histórico.

Por outro lado, qualquer noção que queira aproximar ideologia de "falsa" consciência implicaria a possibilidade de existir alguma forma absolutamente correta de se ver e entender o mundo. No caso da ciência, isto coloca de imediato o problema da verdade - e a tentativa de alcançar a verdade é inerente à atividade científica, mas a história da ciência tem demonstrado o quão ilusória foi a "verdade" de tantas teorias científicas. E no entanto, nenhum cientista desistiria por causa disso de pesquisar a verdade científica.

Ora, qualquer ideologia se refere a uma ideia tida como verdadeira. Se fosse consensual que se trata de uma falsa ideia, um embuste reconhecido como tal, cairíamos no reino das simples mentiras e não das ideologias. Mas uma ideia pode ser verdadeira para alguns e falsa para outros? Evidentemente que sim, pois como já referido, isto é uma situação normal no desenvolvimento de teorias dentro até das ciências ditas exatas.

Um exemplo esclarecedor de ideologia como falsa ideia ocorreu em vários países, e no Brasil em especial, durante os anos da década de 1990 e início da de 2000, e que foi uma faceta do neoliberalismo econômico quando este apregoou que a privatização dos serviços públicos os tornaria mais eficientes. É certamente mais fácil julgar post hoc, e depois se tornou cada vez mais claro que ocorreu o contrário, com a escalada exorbitante dos preços pagos pelos consumidores desses serviços, as fraudes e falências nas empresas privatizadoras, além de problemas técnicos como apagões, no caso da energia elétrica, e outros. Como poderiam se comportar os indivíduos face a uma ideologia que se comprovou posteriormente ser uma ideia falsa? Alguns proponentes dessa ideologia poderiam saber que era uma balela a afirmação de melhorias com a privatização, mas a defendiam porque tinham interesses econômicos na privatização das companhias elétricas, telefônicas, de transportes, siderurgia, mineração - ou seja, para estes não se tratava de ideologia, mas de pura mentira.

Os que, mesmo sabendo da burla, apresentavam o motivo da racionalização e enxugamento das máquinas administrativas das estatais, e que tinham consciência de que isto era uma ideia falsa, divulgavam a ideologia do liberalismo, mas não se pode dizer que criam nessa ideologia, simplesmente defendiam uma versão mentirosa porque ela lhes era conveniente. 
Já os indivíduos que pertenciam à parcela da opinião pública que aceitou a privatização e a defendeu como lógica certamente assumiram-na enquanto uma ideologia, ainda sem saber se seria falsa ou verdadeira, pois não tinham consciência de eventuais manipulações, até porque o argumento se encaixava na propaganda negativa amplamente veiculada pelos meios de comunicação sobre os maus serviços prestados pelas empresas públicas. Por desconhecer a realidade, não ter termos de comparação, ou ainda porque de fato conhecia aspectos negativos comprovados nas empresas estatais, o público as desacreditou e endossou a propaganda neoliberal.

Havia ainda outra possibilidade: pessoas que conheciam melhor a realidade das empresas públicas, como por exemplo alguns de seus funcionários, e de fato acreditavam na ideia neoliberal, porque parecia-lhes que a privatização resolveria os vícios que sabiam existir. Poderíamos dizer que essas pessoas conscientemente acreditaram naquela ideologia, que de forma alguma lhes parecia falsa. Finalmente, poderíamos ter as pessoas que sabiam que se tratava de uma ideia falsa e não compactuaram com ela, de forma que sua consciência do que seria a verdade os impediu de aderir à ideologia.

O esquema apresentado neste exemplo pode ser assim resumido: a realidade nos é conhecida sempre parcialmente, através de diversos tipos de "filtros", que é como se pode descrever a ação de veículos ideológicos, tais como o sistema educacional, os meios de comunicação, etc. Há filtros mais sofisticados que se interpõem perante nós e a realidade, como exemplificado no caso das ciências pelas experiências realizadas em laboratório, mas todas estas visões parciais se integram de alguma forma em nossa consciência, que é onde pode ocorrer o mais perto de um conhecimento total que se poderia ter. Dependendo de como essa consciência foi formada e educada, ela será também seletiva com relação às ideias que aceita ou rejeita, facilitando a adoção de determinadas ideologias e dificultando a de outras.

Há uma relação de paralelismo, portanto, entre ideologia e consciência. No plano filosófico, uma clássica pergunta do conhecimento é saber quem sou. Do ponto de vista exterior, como eu poderia conhecer a totalidade das minhas imagens que se projetam para as demais pessoas, de forma que refletissem meu "verdadeiro" eu? Essas minhas imagens projetadas serão, porém, meu "eu"? O que dizer então da realidade interior que se desvenda apenas através da psicanálise, quando se rompem as barreiras das representações que fazemos de nós mesmos? Talvez a analogia pudesse ser levada ainda mais longe, de forma que o que se convencionou freudianamente chamar de superego fosse um bom exemplo do processo de formação das ideologias, no caso a ideologia que cada um tem a seu respeito, e que aliás acredita com certeza ser verdadeira, pela aplicação de vários filtros mentais.

Fica implícito então que uma ideologia pode-se também referir a uma ideia aceita como verdadeira e que se revele verdadeira. Pode-se, por exemplo, endossar a ideologia do republicanismo, defendendo o interesse pelo bem comum e pela coisa pública, respeitando o que isto acarreta, na forma de um corpo de leis que reforce essa ideologia. Pode-se mesmo acreditar no conjunto dessas ideias, mas divergindo de particularidades ou de aspectos da ideologia que causem desconforto, porque se está convicto de que a longo prazo isto tende a melhorar a vida das pessoas, aumentando as oportunidades de se desfrutar bens como saúde e educação.

A formulação original dos ideólogos franceses, a da "ciência das ideias", pode remeter para o mito da caverna, descrito por Platão no Livro VII de $A$ República. ${ }^{14}$ Neste diálogo socrático, conta-se a história de uma caverna escura onde os habitantes agrilhoados de costas para o Sol vêm apenas as sombras projetadas na parede da caverna. De onde estão não conseguem discernir o ilusório do real, todo o conhecimento do mundo exterior decorre apenas

${ }^{14}$ Platão, A república: ou sobre a justiça (Belém: Universidade Federal do Pará, 2000, Livro VII), 319-324. 
da visão das sombras. Quando um dos prisioneiros consegue se libertar e finalmente olhar a realidade iluminada pelo Sol é que compreende de fato o que eram as projeções na parede. Pode então voltar para o meio dos outros habitantes da caverna, onde é possível ganhar novos conhecimentos, mesmo através das sombras e mesmo tendo contra si os demais acorrentados, que não compreendem como poderiam se libertar das ilusões das sombras.

A alegoria platônica se presta a muitas interpretações, mas no presente contexto creio que uma aplicação imediata dela é que, em princípio, é possível desfazer a trama das ideologias ("sombras"), quando elas encobrem as ideias. Pode-se procurar conhecer a essência das idéias na realidade e desta forma vislumbrar o conhecimento verdadeiro, objetivo confesso da ciência. Por outro lado, o conhecimento para além das sombras certamente evoca o problema já mencionado da conscientização, o que suscita a interrogação mesma da ciência. Ou seja: pode haver uma ciência independente de qualquer ideologia, ou de opiniões ou, como queria Baruch Espinosa, um conhecimento verdadeiro e não dogmático ${ }^{15} \mathrm{E}$ a realidade - se ela (como penso) existe em si mesma de forma independente do homem - pode ser conhecida de forma objetiva e igualmente verdadeira? Devemos manter essas indagações à nossa frente, à medida que forem sendo explorados temas de história das ciências e suas ideologias.

\section{A ideologia na ciência}

A teoria das ideias de Platão é um ensejo também para se fazer uma incursão num pensamento pouco explorado de Marx, mas que tem analogia com a temática da ciência e ideologia e que é o da pertinência de sua apreciação estética. Na Contribuição para a crítica da economia política, ele confessa que, estranhamente, a arte grega parece não depender do desenvolvimento geral da sociedade e conservar um valor permanente, em várias e portanto diferentes condições históricas. ${ }^{16}$ Negaria isto a dependência de uma produção humana das suas bases materiais na sociedade? Por outro lado, parece haver mesmo em toda arte que atravessa os tempos e continua a proporcionar prazer estético um valor "verdadeiro", porque "eterno". É fácil compartilhar da perplexidade de Marx quando se admira a estatuária grega, como na mutilada Afrodite de Cnido ou até mesmo numa imitação romana de arte grega, como na magnífica estátua equestre de Marco Aurélio. ${ }^{17}$

Se a dúvida estética de Marx se aplica à arte grega, poderíamos ir mais longe e perguntar se ela não é válida também para a perfeição da geometria grega. ${ }^{18}$ Embora hoje tenhamos indicações que nosso espaço não seria euclidiano, e mesmo que o espaço euclidiano seja uma aproximação dentro de certos limites, não deixa de nos causar profunda admiração a beleza "permanente" do conhecimento geométrico atingido pelos gregos na obra de Euclides. É como se houvesse também, de modo análogo ao de certas manifestações artísticas, ideias científicas com um tipo de valor "permanente", ainda que suplantadas por novas teorias.

Por outro lado, ocorre que as ideias científicas frequentemente camuflam suas origens extracientíficas, dissimulação geralmente característica em se tratando de ideologias. Como exemplo, pode-se lembrar do mecanicismo newtoniano e do evolucionismo darwinista. Essas

\footnotetext{
15 Para uma discussão do pensamento espinosano articulado com o desenvolvimento histórico da ciência, vide Gildo Magalhães, "A idéia adequada e a contribuição possível de Espinosa à ciência", Revista Brasileira de Filosofia, [vol.] XLV, n” 193 (1999).

${ }^{16}$ Karl Marx, Contribuição para a crítica da economia política, in Os Pensadores, vol. XXXV (São Paulo: Abril, 1974), $130-131$.

${ }^{17}$ Que esteve até algum tempo atrás exposta ao ar livre no centro do Campidoglio romano, e da qual Michelangelo teria afirmado não ser digno nem de lhe fazer o pedestal.

${ }^{18}$ Georges Canguilhem, "O que é uma ideologia científica”, in Ideologia e racionalidade nas ciências da vida, 35.
} 
teorias, embora distanciadas cerca de 150 anos, se fundem na economia política com a ideia de "livre concorrência", tendo uma origem comum no pensamento empirista britânico, e foram amplamente cultivadas justamente na Grã-Bretanha. Com fundamentações diferentes, a livre concorrência divulgada principalmente por Adam Smith e, de maneira indireta, por Thomas Malthus, levou ambos porém a concordarem na conclusão de que as leis da natureza e da religião favoreceriam a "luta pela vida" e a recomendarem a exclusão do Estado como regulador da vida civil. Nessa perspectiva, o mundo pode ser representado por um quadro de leis fixas, onde a própria divindade estaria excluída (a menos de intervenções oportunas em momentos críticos, como acreditava Newton), um mundo em que, ao menos aparentemente, não há imperativos morais.

Ora, no caso de Isaac Newton e Charles Darwin, tratava-se precisamente de justificar o laissez-faire com os olhos da ciência. No último caso, pode-se contrapor a posição política de Darwin à de seu competidor Alfred Wallace, que por ter certas convicções de fundo socialista e ter recusado a interpretação darwinista do papel do acaso na evolução, acabou ficando meio negligenciado pela comunidade científica e política da era vitoriana. ${ }^{19}$

Uns poucos casos marcantes que ocorreram na história da física podem ser resumidamente citados como exemplos da interpenetração das ideologias com as ciências:

- A unidade e a universalidade das forças da física buscadas por Hans Christian Oersted dentro do movimento da Naturphilosophie, por sua vez relacionada com as ideias de Friedrich Schelling sobre as oposições na natureza e as de G.W. F. Hegel sobre um "espírito universal", em constante evolução.

- A formulação do princípio de complementaridade entre ondas e partículas como base da mecânica quântica por Niels Bohr muito deveu às ideias existencialistas de Søren Kierkegaard, interpretação que por sua vez acabou refluindo numa junção do papel do irracionalismo nas teorias psicanalíticas de Gustav Jung com ensinamentos do taoísmo.

- A firme defesa da causalidade no mundo por Albert Einstein derivava de suas leituras de Leibniz, e principalmente de Espinosa, no que tange à possibilidade de conhecimento da realidade pelo ser humano.

Para explicar melhor essas influências ideológicas, pensemos um momento como um físico ou químico poderia considerar, digamos, uma molécula de água. Ele vai nisto transpor um tanto de ideias filosóficas (às vezes até metafísicas) da sua época, que como dito atrás em geral ficam escondidas, dependendo de como irá explicar certos detalhes, como por exemplo os orbitais elétricos (espécie de trajetórias descritas por elétrons) e os spins (quantidades que se associam ao sentido horário ou anti-horário de rotação de entidades subatômicas). Pode haver nisto a possibilidade de que sejam assim representadas até mesmo posições políticas, o que ocorreu efetivamente na física soviética, ao responder à questão do exemplo em causa: se devemos tratar essas entidades subatômicas como coletividades ou individualidades - e a matemática que as descreve poderá mudar em consequência dessas posições. ${ }^{20}$ Qualquer exemplo concreto de articulação das ideologias com as ciências e técnicas será melhor elucidado se levarmos em conta que a inter-relação se dá com o conjunto das atividades humanas, em que todos os componentes podem intervir com pesos diferentes, ou seja, pendendo para uma

\footnotetext{
${ }^{19} \mathrm{O}$ relato de Ricardo Ferreira a esse respeito é dos mais interessantes, pela comparação do pensamento de Darwin com o de Bates e Wallace. Cf. Bates, Darwin, Wallace e a teoria da evolução (Brasília e São Paulo: Universidade de Brasília e Universidade de São Paulo, 1990).

${ }^{20}$ Alexei Kojevnikov, "Freedom, collectivism, and quasiparticles: social metaphors in quantum physics", Historical Studies in the Physical and Biological Sciences, [vol.] 29 (1999).
} 
história em moldes externalistas, e não isoladamente olhando para dentro de uma determinada ciência.

Adicionalmente, eis mais alguns exemplos sucintos e diversos entre si de como se poderiam explorar ideologias científicas num espectro mais amplo da história das ideias e da cultura:

a) $\mathrm{Na}$ pintura, um exemplo famoso é o quadro Os embaixadores, de Hans Holbein (pintado em 1533), em que os enviados de Francisco I da França estão na Londres de Henrique VIII, tentando evitar o cisma com a Igreja de Roma. Junto aos embaixadores estão diversos objetos de cunho científico, como globos terrestre e celestial, gnômon com relógio solar, livros de aritmética e música. Não por acaso, a maioria dos instrumentos está relacionada com as viagens de navegação e as grandes descobertas. Pairando no ar sobre o chão está a impressionante anamorfose de uma caveira, não só um memento da difícil época vivida, mas uma alusão ao domínio do espaço através da perspectiva, o grande feito científico da Renascença. Pode-se ligar todas estas construções metafóricas com a ideia de progresso e sua antítese, a da decadência. ${ }^{21}$

b) A aplicação de novas tecnologias da informática como o cartão bancário transformou o cotidiano, especialmente numa sociedade como a brasileira, em que porções significativas de analfabetos e semianalfabetos, excluídos da sociedade de consumo paradoxalmente puderam passar a ter e acessar contas, como as da previdência social. A evolução nesse campo trouxe o "cartão inteligente", uma aplicação da teoria matemática da informação e da ciência da computação - realizando uma das reivindicações preconizadas pela antiga cibernética. Por outro lado, a cibernética tinha pretensões de controle social das massas, que se poderiam realizar com a informática e se podem rastrear no modelo matemático da realimentação em malha fechada com que descreve certos processos.

c) $\mathrm{Na}$ poesia, pode-se citar o caso de Edgar Allan Poe, que aprendeu uma base científica o suficiente com a engenharia militar que estudou na academia de West Point, a ponto de se tornar um destacado precursor da moderna criptografia em seu conto $O$ escaravelho de ouro. Além disso, ele incursionou pelo lado da inteligência artificial, ao desvendar um famoso "mistério" do século XIX, o autômato jogador de xadrez feito pelo inventor do metrônomo musical, Maelzel, que pretensamente era um robô, mas que Poe provou ser uma fraude engenhosa. Foi o primeiro a propor uma solução para o "paradoxo de Olbers" da astronomia: por que o céu noturno não é totalmente iluminado se o universo é praticamente ilimitado e há um número enorme de fontes de luz? Seu celebrado poema $O$ corvo possui uma rigorosa estrutura, em termos de métrica e rimas, objeto de um ensaio explicativo do próprio Poe e que nada fica a dever a um teorema matemático, sem prejuízo naturalmente da inspirada ideia poética de sua criação. ${ }^{22}$

d) Em termos musicais, o conceito de harmonia, em especial na forma da fuga, praticada por notórios compositores alemães a partir do século XVII, está próximo do desenvolvimento de vários séculos da teoria matemática do infinito, que culminou com a descoberta dos números transfinitos por Georg Cantor no século XIX. A partir do transfinito

\footnotetext{
${ }^{21}$ Um desenvolvimento mais detalhado deste exemplo se encontra em Gildo Magalhães, "Ciências e reformas religiosas no Renascimento", Revista Camoniana, [v.] 14, (2003): 385-407. Para outras relações sobre pintura e ciência, vide o ensaio de Henriette Bessis, "A imagem da ciência na pintura”, em A ciência e o imaginário (Brasília: Universidade de Brasília, 1994), 159-190.

${ }^{22}$ Edgar Allan Poe, "O escaravelho de ouro", "O corvo", "Filosofia da composição" e "Criptografia”, em Fiç̧ão completa, poesia e ensaios (Rio de Janeiro: Nova Aguilar, 1986), 130-160, 901-995, 911-920 e 1009-1019; e "Maelzel's chess player”, em Edgar Allan Poe, The complete tales of mystery and imagination (Minneapolis: Amaranth, 1984), 551-566. A resposta de Poe para o problema do céu noturno está em seu poema em prosa "Eureca", discutido em Edward Harrison, A escuridão da noite: um enigma do universo (Rio de Janeiro: Jorge Zahar, 1995), 169-178.
} 
por ele chamado de "álefe-um”, temos um conjunto infinito e não enumerável, cujo processo de formação tem analogia com o desenvolvimento temático musical. Isto se dá porque no sistema tonal bem temperado uma composição não se transforma melodicamente de maneira fixa e estática, mas redefinindo e desenvolvendo sem cessar as relações musicais, numa constante "mudança da mudança" - algo que pode ser posto em correspondência com a existência de pontos no contínuo de números reais representados pela reta. ${ }^{23} \mathrm{O}$ que importa na música assim composta é a expressão das ideias musicais e a forma como elas interagem dentro de um "todo", ou seja, uma forma de pensamento que se expressa sensualmente. Essa característica da relação do uno com o múltiplo em música é da mesma ordem que se encontra no citado processo de criação dos números e conjuntos transfinitos de ordem superior - e na poesia, assim como na música, isto é expresso por meio do uso de "metáforas" generalizadas como recurso cognitivo.

Utilizando o conceito de ideologia de forma às vezes mais ampla ou mais restrita, mas necessariamente flexível, pode-se entender melhor como se dá essa produção humana chamada ciência. Ao desvelar as bases desta produção, resulta também uma crítica das atividades científicas e tecnológicas, enquanto motivações humanas.

\footnotetext{
${ }^{23}$ Para conferir basta escutar como exemplo a Sonata no 5, op. 24 ("Primavera") de Beethoven, para violino e piano.
} 